\title{
Administration of Greek Royal Jelly produces fast response in neurotransmission of aged Wistar male rats
}

\author{
Justyna Pyrzanowska', Agnieszka Piechal', Kamilla Blecharz-Klin', Ilona Joniec-Maciejak', \\ Konstantia Graikou², Joanna Chinou'², Ewa Widy-Tyszkiewicz ${ }^{1}$ \\ 1 Department of Experimental and Clinical Pharmacology, Medical University, Warsaw, Centre for Preclinical Research \\ and Technology (CePT), Warsaw, Poland \\ 2 Department of Pharmacognosy and Chemistry of Natural Products, School of Pharmacy, University of Athens, Athens, \\ Greece
}

Pyrzanowska J, Piechal A, Blecharz-Klin K, Joniec-Maciejak I, Graikou K, Chinou J, Widy-Tyszkiewicz E. Administration of Greek Royal Jelly produces fast response in neurotransmission of aged Wistar male rats. J Pre-Clin Clin Res. 2015; 9(2): 151-157. doi: 10.5604/18982395.1186497

\begin{abstract}
Introduction. Royal Jelly (RJ) is a popular bee-derived product used widely in European and Asian traditional medicine. RJ has some pharmacological activities to support health and longevity as well as prevent ageing.

Objectives. To evaluate whether a short-term 6-day Royal Jelly administration is able to induce behavioural and neurochemical effects in aged rats.

Materials and method. RJ (previously chemically characterized by GC-FID and GC-MS) was given to 18-month-old male Wistar rats (100 and 500 mg of powder/kg b.w./day) in subcutaneous injection for 6 days. Spatial memory was assessed in a water maze. Afterwards, the level of neurotransmitters, their metabolites and turnover in the selected brain regions were estimated by HPLC.

Results. Short-term RJ administration did not change spatial memory in aged rats in the water maze, although it was sufficiently active to modify most of all the serotonergic and dopaminergic transmission in the prefrontal cortex and hippocampus.

Conclusion. The obtained results indicate that Royal Jelly is able to affect very quickly the neurotransmission in the brain structures responsible for cognitive performance; however, short-term administration is not sufficient to exert behavioural consequences.
\end{abstract}

\section{Key words}

Royal Jelly, water maze, spatial learning, prefrontal cortex, hippocampus, dopamine, serotonin

\section{INTRODUCTION}

Royal Jelly (RJ) is a natural product obtained from bees. $\mathrm{RJ}$ is a specific substance abundant in nutrients produced in the hypopharyngeal and mandibular glands of worker honeybees (Apis mellifera) to feed the queen bee larva, as well as the adult queen herself. This substance fulfills the criteria of functional foods and its ingredients can specifically affect body functions, building up explicit outcome beyond its nutritional value, such as health maintenance and wellness [1]. RJ has been used for a long time as a dietary supplement in complementary medicine. RJ contains proteins, free amino acids, lipids, carbohydrates, vitamins, minerals and substantial amount of water. It also comprises some bioactive substances, e.g., 10-hydroxy-trans-2-decenoic acid (HDEA), monophosphate (AMP N(1)-oxide), and phenolic compounds such as flavonoids.

RJ has various pharmacological activities, described in preclinical research as anti-oxidant, anti-hypercholesterolemic, anti-hyperglycemic and anti-inflammatory features. RJ is able to affect carbohydrate and lipid metabolism - it ameliorates insulin resistance, decreases plasma levels of insulin and

Address for correspondence: Ewa Widy-Tyszkiewicz, Department of Experimental and Clinical Pharmacology, Medical University, Warsaw, Centre for Preclinical Research and Technology (CePT), Warsaw, Poland

E-mail: etyszkiewicz@wum.edu.pl

Received: 31 July 2015; accepted: 09 October 2015 triglycerides, and lowers systolic blood pressure in rats [2]. RJ may finally be effective for the prevention of age-related changes, especially within the brain and blood vessels. The active RJ compound monophosphate may also influence the performance of nervous system cells [3]. Another component of RJ, an unsaturated fatty acid, HDEA, affects the brainderived neurotrophic factor (BDNF) production [4] and neurogenesis in neural stem/progenitor cells [5]. Royal Jelly may also have beneficial influence on learning and memory; it facilitates restoration of the cognitive ability in trimethyltinintoxicated mice [6] and alleviates the adverse effects of intracerebroventricular injection of streptozocin [7]. The adult SD rats in D-galactose sub-acutely aging model [8], as well as otherwise healthy aged Wistar rats [9], presented improved memory in the water maze after prolonged oral RJ treatment. Chronic RJ administration could also influence brain neurotransmission, especially through impact on dopamine and serotonin metabolism in the prefrontal cortex of aged animals [9].

The presented study investigates the effects of a 6-day subcutaneous RJ administration (100 and 500mg of powder/ $\mathrm{kg}$ b.w./day) on cognitive abilities in a Morris water maze, and on the neurotransmitter level in the prefrontal cortex, hippocampus, striatum and hypothalamus of old rats. The experiment sought to determine whether short-term administration of RJ is sufficient to change the cognitive performance of old rats, as well as modify neurotransmitter 
levels. The behavioural and biochemical effects of such an exposure to Royal Jelly in naturally aged Wistar male rats are not yet known.

\section{MATERIALS AND METHOD}

Animals. In the presented study, 18-month-old male Wistar Albino Glaxo (WAG) rats were used $(n=24)$. All animal testing was carried out in accordance with Directive 2010/63EU of the European Parliament and of the Council of 22 September 2010 on the protection of animals used for scientific purposes, after approval of the Ethical Committee for Animal Experiments at the Medical University of Warsaw, Poland.

Chemicals. Royal Jelly originating from Apis mellifera was provided by ATTIKI bee Culturing Co., Greece. $1 \mathrm{~kg}$ of RJ sample was lyophilized, a part of which was predicted to the treatment and a small amount $(12 \mathrm{~g})$ extracted and analyzed, first by GC-FID and next by GC-MS, as previously described in detail [9]. Identification of the compounds was based on comparison of their retention indices (RI), obtained by using n-alkanes (C9-C25) and on comparison of their EI-mass spectra with reference compounds, or on the basis of their general fragmentation using reference spectra.

Royal Jelly administration. In the experiment, RJ powder was added to $0.9 \% \mathrm{NaCl}$ solution $(1 \mathrm{ml})$ to form a suspension that was given to the rats in an s.c. injection 1 hour before water maze testing. The animals were randomized and divided into 3 groups:

1) RJ100 - treated with $100 \mathrm{mg}$ of powder/kg b.w./day, $\mathrm{n}=8$;

2) RJ500 - 500mg of powder/kg b.w./day, $\mathrm{n}=8$;

3) control rats (Con), given the $1 \mathrm{ml}$ of $0.9 \% \mathrm{NaCl}$ solution s.c., $\mathrm{n}=8$.

The rats were treated for 6 days during the period of behavioural testing.

High Pressure Liquid Chromatography (HPLC) assessment. Biochemical measurements were carried out 24 hours after the last behavioural trial. The rats were decapitated, their brains immediately removed and dissected out on an ice-cold plate by the method of Glowinski and Iversen [10], into the following regions: prefrontal cortex, hippocampus, hypothalamus and striatum. The concentrations of monoamines and their metabolites in selected brain regions were estimated. Each tissue was placed in a dry-ice-cooled polypropylene vial, weighed, and stored in a deep freezer at $-80^{\circ} \mathrm{C}$ until assayed. To precipitate proteins, tissues were homogenized in $1 \mathrm{ml}$ of ice-cold $0.1 \mathrm{M}$ perchloric acid ( $\mathrm{HClO} 4)$, and centrifuged $(13,000 \mathrm{~g}$ for $15 \mathrm{~min})$. The supernatant was filtered $(0.2 \mu \mathrm{m}$ pore size filter; Whatman) and examined for neurotransmitter content. Dopamine (DA; standard substance supplied by RBI), its metabolite, 3,4-dihydroxyphenylacetic acid (DOPAC; RBI); 5-hydroxytryptamine (5-HT; Sigma); 5-hydroxyindolacetic acid (5-HIAA; Sigma); 3,4-dihydroxyphenylethanolamine (NA; Sigma), 3-methoxy-4-hydroxyphenylglycol (MHPG; Sigma) and homovanillic acid (HVA; Sigma) - were measured by high pressure liquid chromatography HPLC with electrochemical detection (L-3500Adetector;Merck) and a glassy carbon-working electrode. The electrochemical potential was set at $0.8 \mathrm{~V}$ with respect to a silver/silver chloride $(\mathrm{Ag} / \mathrm{AgCl})$ reference electrode. The mobile phase comprised $58 \mathrm{mM}$ sodium phosphate (Sigma), $31 \mathrm{mM}$ citric acid (Sigma), $1 \mathrm{mM}$ octane sulfonic acid (Aldrich), and $27 \mu \mathrm{M}$ ethylenediaminetetraacetic acid (EDTA;Sigma) in deionized, distilled $(18.3 \mathrm{~m} \Omega)$ ultrapure water containing $1 \%$ acetonitrile (Merck) and 12\% methanol (Merck). Monoamines were separated on a C-18 column $\left(250 \mathrm{~mm} \_4 \mathrm{~mm}\right.$, reverse phase, Nucleosil, $5 \mu \mathrm{m}$ particle size; Macherey-Nagel, Germany) and the mobile phase flow rate was maintained at $0.8 \mathrm{ml} / \mathrm{min}$. Samples were quantified by comparison with standard solutions (external calibration) and concentrations calculated with Eurochrom 2000 software (Knauer, Germany). Contents of neurotransmitters and metabolites were expressed as $\mathrm{ng} / \mathrm{ml}$ of the homogenates. The final amount of monoamines in the tissue sample was expressed as ng/g of wet tissue.

Behavioural test - water maze test assessing spatial memory. The animals were tested in a modified version of the Morris water maze test in the same algorithm as in [9] that comprised both cued and non-cued trials.

The experiment was performed during the light phase of the cycle (between 08.00-16.00h). First, the animals were trained to find a hidden platform in a swimming pool (a white platform, circular, diameter $-140 \mathrm{~cm}$, depth $-50 \mathrm{~cm}$ ) that was filled to a height of $30 \mathrm{~cm}$ above the base with water at a temperature of $23^{\circ} \mathrm{C}$. The pool was divided into 4 quadrants, arbitrarily designated as Northeast (NE), Northwest (NW), Southeast (SE) and Southwest (SW). A submerged plexiglass platform $(10 \mathrm{~cm} \times 10 \mathrm{~cm})$ was hidden $1 \mathrm{~cm}$ below the water surface and placed at a constant location in the center of the SE quadrant. During acquisition of the spatial navigation task, all groups were given one session of 4 trials each day (dayl - 4; trial 1 - 16) divided by a 60s inter-trial interval. Each trial was started by placing a rat with its face toward the wall of the pool at one of 3 start points. The start location was varied in each training trial and changed each day. The trial was terminated when the animal entered the platform. If not achieved, then after 60 s of swimming it was placed on the platform by the experimenter for $15 \mathrm{~s}$. Spatial memory was evaluated in the probe trial, on $5^{\text {th }}$ day (trial 17). The platform was removed and animals allowed to swim for $60 \mathrm{~s}$. The visible platform test was carried out on the $6^{\text {th }}$ day. The animals had to find the well-signed platform placed $1 \mathrm{~cm}$ over the water surface in 4 trials from different starting points to the cued target.

Data from the water maze (latencies to locate the platform, distance travelled, swimming speed, number of crossings in the target area, and time spent in the goal quadrant) were registered by a collecting system and analyzed by Chromotrack software (Chromotrack, San Diego Instruments, USA).

Statistical analysis. Statistical analysis was carried out using Statistica v.10 software (Statsoft, PL). All the results were presented as mean values \pm SE. The following statistical tests were used: two-way repeated measures ANOVA (dose $\mathrm{x}$ day) - to assess differences during acquisition in the watermaze testing and visible platform test; Kruskal-Wallis and chi $^{2}$ tests - to assess differences during memory test and in biochemical examination; Mann - Whitney test - for estimation the differences between groups within particular parameters during memory test and in biochemical tests. All the hypotheses tested used a significance level of 0.05 . 


\section{RESULTS}

Water maze results - 3.1.1.

Acquisition trials (days 1-4, trials 1-16). The escape latency - ANOVA results did not show a significant mean effect for particular days:

day $1: \mathrm{F}_{(2,21)}=0.24 ; \mathrm{p}<0.79$

day $2: \mathrm{F}_{(2,21)}=0.28 ; \mathrm{p}<0.76$

day 3: $\mathrm{F}_{(2,21)}=0.12 ; \mathrm{p}<0.89$;

day $4: \mathrm{F}_{(2,21)}^{(2,2)}=2.88 ; \mathrm{p}<0.08$

The values of mean total escape latency during learning (days 1-4) were the same within the groups (RJ100: $34.17 \pm 1.92 \mathrm{~s}$; RJ500: 30.27 $\pm 1.95 \mathrm{~s}$; Con: $32.45 \pm 1.99 \mathrm{~s}),\left(\mathrm{F}_{(2,21)}=0.46, \mathrm{p}<0.64\right)$.

The swim distance - ANOVA analysis for a particular day of training is presented as follows:

day 1 : $\mathrm{F}_{(2,21)}=1.9 ; \mathrm{p}<0.17$;

day 2: $\mathrm{F}_{(2,21)}^{(2,21)}=0.45 ; \mathrm{p}<0.6$;

day 3: $\mathrm{F}_{(2,21)}=1.11 ; \mathrm{p}<0.3$;

day 4: $\mathrm{F}_{(2,21)}^{(2,21)}=7.91 ; \mathrm{p}<0.003$.

The total swim distance was the same among the groups (RJ100: 8.58 $\pm 0.61 \mathrm{~m}$; RJ500: 6.94 $\pm 0.48 \mathrm{~m}$; Con: 6.47 $\pm 0.45 \mathrm{~m}$ ), $\left(\mathrm{F}_{(2,21)}=3.08, \mathrm{p}<0.06\right)$.

The swimming speed - ANOVA analysis for a particular day of training is given below:

day $1: \mathrm{F}_{(2,21)}=1.9 ; \mathrm{p}<0.17$;

day 2: $\mathrm{F}_{(2,21)}^{(21)}=0.45 ; \mathrm{p}<0.64$;

day 3: $\mathrm{F}_{(2,21)}=1.11 ; \mathrm{p}<0.35$;

day 4: $\mathrm{F}_{(2,21)}=7.91, \mathrm{p}<0.003$;

and in the whole training (days 1-4) (RJ100: 0.15 $\pm 0.011 \mathrm{~m} / \mathrm{s}$; RJ500: $0.12 \pm 0.009 \mathrm{~m} / \mathrm{s}$; Con $\left.0.11 \pm 0.008 \mathrm{~m} / \mathrm{s} ; \mathrm{F}_{(2,21)}=3.08 ; \mathrm{p}<0.07\right)$.

Probe trial - memory test (day 5, trial 17). The number of crossings over the area of the previous platform position in the SE quadrant was the same among groups (Con: $2.5 \pm 0.46$; RJ100: 2.5 \pm 1.05 ; RJ500: 2.88 \pm 0.64 ; Kruskal-Wallis test: $\left.\mathrm{H}_{(2,24)}=6.47 ; \mathrm{p}<1.03\right)$. The animals treated with Royal Jelly (RJ100: 16.64 $\pm 3.08 \mathrm{~s}$, RJ500: 13.44 $\pm 1.48 \mathrm{~s}$ ) spent the same time in the target quadrant (SE), where the platform was situated during acquisition trials as did the control animals (Con: $14.57 \pm 1.02 \mathrm{~s} ; \mathrm{H}_{(2,24)}=0.61 ; \mathrm{p}<0.74$ ). There were also no differences among groups in the time spent in other quadrants (SW: $\mathrm{H}_{(2,24)}=4.58 ; \mathrm{p}<0.1, \mathrm{NW}: \mathrm{H}_{(2,24)}=2.11 ; \mathrm{p}<0.35$, $\left.\mathrm{NE}: \mathrm{H}_{(2,24)}=0.26 ; \mathrm{p}<0.88\right)$. The path (Con: $16.96 \pm 2.1 \mathrm{~m} ; \mathrm{RJ} 100$ : $19.74 \pm 2.75 \mathrm{~m}$; RJ500: $\left.15.17 \pm 0.83 \mathrm{~m} ; \mathrm{H}_{(2.24}=2.83 ; \mathrm{p}<0.24\right)$ and the swimming speed (Con: $0.28 \pm 0.03 \mathrm{~m} / \mathrm{s} ; \mathrm{RJ} 100: 0.33 \pm 0.05 \mathrm{~m} / \mathrm{s}$; RJ500: $\left.0.25 \pm 0.01 \mathrm{~m} / \mathrm{s} ; \mathrm{H}_{(2,24)}=2.84 ; \mathrm{p}<0.24\right)$ were the same among groups during the probe trial.

Visible platform test (day 6, trials 18-21). The values of

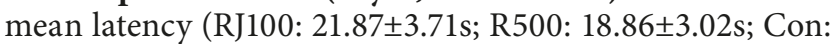
$21.65 \pm 3.17 \mathrm{~s})\left(\mathrm{F}_{\mathrm{C} 21)}=0.18, \mathrm{p}<0.84\right)$ as well as the path (RJ100: $3.65 \pm 0.37 \mathrm{~m}$; RJ500: $3.4 \pm 0.34 \mathrm{~m}$; Con: $3.75 \pm 0.32 \mathrm{~m})\left(\mathrm{F}_{(2,21)}=0.21\right.$, $\mathrm{p}<0.81)$ and the swimming speed (Con: $0.51 \pm 0.04 \mathrm{~m} / \mathrm{s} ; \mathrm{RJ} 100$ : $0.5 \pm 0.05 \mathrm{~m} / \mathrm{s}$; RJ500: $0.46 \pm 0.05 \mathrm{~m} / \mathrm{s})\left(\mathrm{F}_{(2,21)}=0.21, \mathrm{p}<0.8\right)$ were the same among groups.

Biochemical results - 3.2.1.

Chemical analysis of the studied sample of RJ. Detailed results of chemical analysis of studied Greek Royal Jelly have previously been presented in [9]. The analyzed sample appeared very rich in fatty acids, 10-hydroxy-2-decenoic acid, 10-hydroxydecanoic acid and sebacic acid, which are the main RJ acids according to the literature data, as well
Table 1. Major constituents of the analyzed sample of Royal Jelly

\begin{tabular}{ll}
\hline$\%$ & Compound \\
\hline 42.32 & 10-Hydroxy-2-decenoic acid \\
\hline 19.56 & 10-Hydroxydecanoic acid \\
\hline 6.16 & 8-Hydroxyoctanoic acid \\
\hline 5.21 & 4-Decene-1,10-dioic acid \\
\hline 5.00 & Sebacic acid \\
\hline 4.59 & 3,10-Dihydroxydecanoic acid \\
\hline 4.43 & 9-Hydroxy-2-decenoic acid \\
\hline 1.30 & 11-Hydroxydodecanoicacid \\
\hline
\end{tabular}

as 8-hydroxyoctanoic acid, 3-hydroxydecanoic acid and 3,10-dihydroxydecanoic acid (Tab. 1).

Monoamine level in selected brain regions. The levels of monoamines and their metabolites, as well as the metabolite DOPAC/DA, HVA/DA, 5-HIAA/5-HT and MHPG/NA ratio values in the prefrontal cortex, hippocampus, hypothalamus and striatum after short-term RJ administering, are collected in Table 2.

Prefrontal cortex. In the prefrontal cortex, statistically significant differences were noted in the level of serotonin (5-HT: $\mathrm{H}_{(2,23)}=14.44, \mathrm{p}<0.0007$, Kruskal Wallis ANOVA) as well as in its metabolite 5-HIAA $\left(\mathrm{H}_{(2,23)}=16.36, \mathrm{p}<0.0003\right)$. Both RJ-treated groups of rats had significantly decreased 5-HT and 5-HIAA contents when compared with controls (Tab. 1; Fig. 1.A). The 5-HIAA/5-HT ratio differed among groups $\left(\mathrm{H}_{(2,23)}=7.57, \mathrm{p}<0.02\right)$. The metabolite turnover was lower in RJ100 rats vs. Con and RJ500 (Tab. 1; Fig. 1.B).

There were no differences in other monoamines level in the prefrontal cortex $\left(\mathrm{DA}: \mathrm{H}_{(2,23)}=1.17 ; \mathrm{p}<0.56, \mathrm{NA}: \mathrm{H}_{(2,23)}=2.84\right.$; $\mathrm{p}<0.24)$, but noradrenaline and dopamine metabolites: MHPG and DOPAC concentration altered within groups $\left(\mathrm{H}_{(2,23)}=8.94 ; \mathrm{p}<0.01\right.$ and $\mathrm{H}_{(2,23)}=9.76 ; \mathrm{p}<0.008$, respectively (Tab.1; Fig. 2.A)). This did not concern homovanillic acid $\left(\mathrm{H}_{(2,23)}=1.57 ; \mathrm{p}<0.46\right)$. The RJ100 group had increased MHPG content in comparison to control rats and to the RJ500 group. DOPAC level was greater in both RJ-administered groups. The DOPAC/DA and also $\mathrm{MHPG} / \mathrm{NA}$ ratio values changed within groups $\left(\mathrm{H}_{(2,23)}=11.17 ; \mathrm{p}<0.004\right.$ and $\mathrm{H}_{(2,23)}=10.1$; $\mathrm{p}<0.006$, respectively) but not HVA/DA $\left(\mathrm{H}_{(2,23)}=2.1 ; \mathrm{p}<0.35\right)$. The dopamine metabolite turnover was higher in RJ100 and RJ500 groups vs. control animals (Tab.1; Fig. 2.B). The noradrenaline metabolite turnover increased only in RJ100 rats when compared with controls (Tab. 1; Fig. 2.C).

Hippocampus. Statistically significant differences in hippocampal monoamine content among the groups of rats were observed in serotonin levels $\left(\mathrm{chi}^{2}=6.04, \mathrm{p}<0.049\right)$. Further analysis (post-hoc tests) proved an increase in 5-HT concentration in the R500 group in comparison to control rats (Tab. 1, Fig. 3.A). There were no differences in 5-HIAA concentrations among rats $\left(\mathrm{H}_{(2,24)}=0.845 ; \mathrm{p}<0.66\right)$ but the 5 -HIAA/5-HT ratio values were different in examined animals $\left(\mathrm{H}_{(2,23)}=11.84 ; \mathrm{p}<0.003\right)$. They were decreased in both RJ100 and RJ500 groups in comparison to Con (Tab. 1; Fig. 3.B).

There were also differences among groups in MHPG concentration $\left(\mathrm{H}_{(2,24)}=12.71 ; \mathrm{p}<0.002\right)$, as well as in $\mathrm{MHPG} / \mathrm{NA}$ ratio values $\left(\mathrm{H}_{(2,24)}=15.19 ; \mathrm{p}<0.0005\right)$. MHPG levels were 
Table 2. Effects of short-term oral administration of Royal Jelly on monoamine and metabolite levels $( \pm \mathrm{SE}$ ) as well as metabolite turnover in selected brain regions in aged male rats

\begin{tabular}{|c|c|c|c|c|c|}
\hline \multirow{2}{*}{$\begin{array}{l}\text { Monoamine and metabolite levels } \\
\text { in } \mathrm{ng} / \mathrm{g} \text { of wet tissue }\end{array}$} & \multicolumn{5}{|c|}{ Brain region } \\
\hline & Group & Prefrontal cortex & Hippocampus & Hypothalamus & Striatum \\
\hline \multirow[t]{3}{*}{ NA } & Con & $418.12 \pm 13.03$ & $428.17 \pm 23.9$ & $1127.16 \pm 143.8$ & $379.74 \pm 65.55$ \\
\hline & RJ100 & $394.05 \pm 13.73$ & $438.85 \pm 19.57$ & $1273.72 \pm 69.56$ & $338.55 \pm 55.3$ \\
\hline & RJ500 & $406.48 \pm 8.38$ & $418.32 \pm 12.14$ & $1166.09 \pm 53.82$ & $317.34 \pm 34.56$ \\
\hline \multirow[t]{3}{*}{ MHPG } & Con & $29.23 \pm 6.03$ & $20.32 \pm 2.47$ & $78.77 \pm 2.69$ & $103.59 \pm 4.73$ \\
\hline & RJ100 & $48.94 \pm 3.15^{* *}$ & $14.26 \pm 1.43$ & $86.3 \pm 3.03$ & $94.79 \pm 6.14$ \\
\hline & RJ500 & $32.52 \pm 3.33$ & $9.01 \pm 0.7^{* * *}$ & $75.98 \pm 2.97$ & $89.6 \pm 3.39$ \\
\hline \multirow[t]{3}{*}{ MHPG/NA } & Con & $0.07 \pm 0.02$ & $0.05 \pm 0.005$ & $0.08 \pm 0.01$ & $0.34 \pm 0.06$ \\
\hline & RJ100 & $0.12 \pm 0.01^{* *}$ & $0.03 \pm 0.003^{*}$ & $0.07 \pm 0.01$ & $0.34 \pm 0.06$ \\
\hline & RJ500 & $0.08 \pm 0.01$ & $0.02 \pm 0.002^{* * *}$ & $0.07 \pm 0.01$ & $0.31 \pm 0.04$ \\
\hline \multirow[t]{3}{*}{ DA } & Con & $75.09 \pm 29.37$ & $238.67 \pm 125.2$ & $400.52 \pm 220.96$ & $6869.85 \pm 1093.36$ \\
\hline & RJ100 & $30.66 \pm 3.9$ & $163.29 \pm 79.18$ & $572.68 \pm 214.46$ & $5709.96 \pm 960.57$ \\
\hline & RJ500 & $77.13 \pm 47.46$ & $207.66 \pm 149.13$ & $428.47 \pm 172.27$ & $5604.14 \pm 852.66$ \\
\hline \multirow[t]{2}{*}{ DOPAC } & Con & $56.62 \pm 11.46$ & $91.06 \pm 16.37$ & $95.45 \pm 42.35$ & $813.21 \pm 121.59$ \\
\hline & RJ100 & $95.9 \pm 4.4^{* *}$ & $82.65 \pm 15.02$ & $120.05 \pm 36.81$ & $616.65 \pm 96.83$ \\
\hline \multirow[t]{3}{*}{ DOPAC/DA } & Con & $1.08 \pm 0.18$ & $4.43 \pm 2.93$ & $0.30 \pm 0.03$ & $0.20 \pm 0.08$ \\
\hline & RJ100 & $3.49 \pm 0.49 * * *$ & $1.36 \pm 0.45$ & $0.24 \pm 0.02$ & $0.13 \pm 0.02$ \\
\hline & RJ500 & $3.49 \pm 0.59 * *$ & $1.98 \pm 0.52$ & $0.34 \pm 0.03$ & $0.15 \pm 0.02$ \\
\hline \multirow[t]{3}{*}{ HVA } & Con & $27.16 \pm 6.23$ & $11.03 \pm 5.73$ & $28.04 \pm 11.52$ & $441.97 \pm 23.15$ \\
\hline & RJ100 & $19.07 \pm 5.8$ & $8.58 \pm 2.46$ & $39.68 \pm 10.58$ & $328.05 \pm 54.41$ \\
\hline & RJ500 & $31.41 \pm 6.69$ & $8.86 \pm 5.69$ & $36.35 \pm 10.37$ & $386.11 \pm 50.7$ \\
\hline \multirow[t]{3}{*}{ HVA/DA } & Con & $0.69 \pm 0.33$ & $0.09 \pm 0.03$ & $0.11 \pm 0.03$ & $0.057 \pm 0.003$ \\
\hline & RJ100 & $0.68 \pm 0.2$ & $0.13 \pm 0.07$ & $0.09 \pm 0.01$ & $0.058 \pm 0.003$ \\
\hline & RJ500 & $0.82 \pm 0.17$ & $0.10 \pm 0.04$ & $0.10 \pm 0.01$ & $0.076 \pm 0.007^{* *}$ \\
\hline \multirow[t]{3}{*}{ HVA/NA } & Con & $0.07 \pm 0.02$ & $0.03 \pm 0.02$ & $0.03 \pm 0.01$ & $1.58 \pm 0.3$ \\
\hline & RJ100 & $0.05 \pm 0.01$ & $0.02 \pm 0.01$ & $0.03 \pm 0.01$ & $1.38 \pm 0.43$ \\
\hline & RJ500 & $0.08 \pm 0.02$ & $0.02 \pm 0.01$ & $0.03 \pm 0.01$ & $1.37 \pm 0.26$ \\
\hline \multirow[t]{3}{*}{$5-\mathrm{HT}$} & Con & $454.39 \pm 15.08$ & $295.28 \pm 29.86$ & $756.74 \pm 29.86$ & $508.5 \pm 75.34$ \\
\hline & RJ100 & $300.76 \pm 18.93^{* * *}$ & $353.75 \pm 53.59$ & $861.66 \pm 28.25$ & $446.71 \pm 30.25$ \\
\hline & RJ500 & $319.36 \pm 14.09^{* * *}$ & $437.42 \pm 34.86^{* *}$ & $825.04 \pm 21.5$ & $429.99 \pm 33.39$ \\
\hline & RJ100 & $132.5 \pm 10.33^{* * *}$ & $205.79 \pm 17.04$ & $539.3 \pm 22.35$ & $340.2 \pm 20.1$ \\
\hline & RJ500 & $173.21 \pm 8.33^{* * *}$ & $230.9 \pm 18.97$ & $608.49 \pm 40.94$ & $397.31 \pm 32.73$ \\
\hline \multirow[t]{3}{*}{ 5-HIAA/5-HT } & Con & $0.61 \pm 0.05$ & $0.77 \pm 0.03$ & $0.75 \pm 0.05$ & $0.91 \pm 0.07$ \\
\hline & RJ100 & $0.44 \pm 0.02 *$ & $0.63 \pm 0.05^{*}$ & $0.63 \pm 0.03$ & $0.78 \pm 0.06$ \\
\hline & RJ500 & $0.55 \pm 0.03$ & $0.53 \pm 0.01^{* * *}$ & $0.73 \pm 0.03$ & $0.93 \pm 0.05$ \\
\hline
\end{tabular}

${ }^{*} p<0.05 ;{ }^{* *} p<0.01 ;{ }^{* * *} p<0.001$ (vs. Con, Mann-Whitney test)

diminished in RJ500 vs. Con and vs. RJ100 (Tab.1; Fig. 4.A). The metabolite turnover decreased along with the increase in the dose of RJ (Tab.1; Fig. 4.B).

There were no changes in other monoamines and their metabolite concentrations in the hippocampus:

NA: $\mathrm{H}_{(2,24)}=1.1 ; \mathrm{p}<0.58$;

HVA: $\stackrel{\mathrm{H}}{(2,24)}^{2}=1.36 ; \mathrm{p}<0.51$;

DA: $\mathrm{H}_{(2,24)}=0.2 ; \mathrm{p}<0.91$;

DOPAC: $\mathrm{H}_{(2,24)}=0.56 ; \mathrm{p}<0.76$;

DOPAC/DA ratio: $\mathrm{H}_{(2,24)}=0.41 ; \mathrm{p}<0.82$;

HVA/DA ratio: $\mathrm{H}_{(2,24)}=0.06 ; \mathrm{p}<0.97$.

Striatum. In the striatum, alterations in HVA/DA ratio were seen $\left(\mathrm{H}_{(2,23)}=8.14 ; \mathrm{p}<0.017\right)$. The dopamine turnover was higher in RJ500 vs. Con and also vs. RJ100 (Tab. 1; Fig. 5).

There were no differences in the other tested monoamine and metabolite concentrations or metabolite turnover value in the striatum:

DA: $\mathrm{H}_{(2,24)}=2.89 ; \mathrm{p}<0.24$;

DOPAC: $\mathrm{H}_{(2,24)}=3.52 ; \mathrm{p}<0.17$;

DOPAC/DA ratio: $\mathrm{H}_{(2,24)}=3.65 ; \mathrm{p}<0.16$;

NA: $\mathrm{H}_{(2,24)}=0.18 ; \mathrm{p}<0.91$;

HVA: $\stackrel{(2,24)}{\mathrm{H}}_{(2,23)}=3.64 ; \mathrm{p}<0.16$;
MHPG: $\mathrm{H}_{(2,24)}=4.3 ; \mathrm{p}<0.12$;

MHPG/NA ratio: $\mathrm{H}_{(2,24)}=0.07 ; \mathrm{p}<0.97$;

5-HT: $\mathrm{H}_{(2,24)}=0.32 ; \mathrm{p}<0.85$;

5-HIAA: $\mathrm{H}_{(2,24)}=3.78 ; \mathrm{p}<0.15$;

5-HIAA/5-HT ratio: $\mathrm{H}_{(2,24)}=2.8, \mathrm{p}<0.25$.

Hypothalamus. The concentrations of dopamine and its metabolite DOPAC in the hypothalamus were not changed (DA: $\mathrm{H}_{(2,24)}=2.66 ; \mathrm{p}<0.26$; DOPAC: $\mathrm{H}_{(2,24)}=2.72 ; \mathrm{p}<0.26$ ); however, statistically significant differences were noted in the DOPAC/DA ratio values $\left(\mathrm{H}_{(2,24)}=8.06 ; \mathrm{p}<0.02\right)$ between RJ-treated rats (Tab. 1). HVA/DA ratio remained the same $\left(\mathrm{H}_{(2,24)}=1.51 ; \mathrm{p}<0.47\right)$.

There were no changes in any other monoamines, their metabolite concentration nor in as in metabolite turnover in the hypothalamus:

5-HT: $\mathrm{H}_{(2,24)}=2.66 ; \mathrm{p}<0.26$;

5 -HIAA: $\mathrm{H}_{(2,24)}=2.66 ; \mathrm{p}<0.26$;

5 -HIAA/5-HT ratio: $\mathrm{H}_{(2,24)}=4.87 ; \mathrm{p}<0.09$;

NA: $\mathrm{H}_{(2,24)}=1.34 ; \mathrm{p}<0.51$;

HVA: $\stackrel{\mathrm{H}}{(2,24)}^{2}=1.82 ; \mathrm{p}<0.4$;

MHPG: $\stackrel{(2,2)}{\mathrm{H}}_{(2,24)}=5.45 ; \mathrm{p}<0.07$;

MHPG/NA ratio: $\mathrm{H}_{(2,24)}=0.72 ; \mathrm{p}<0.7$. 


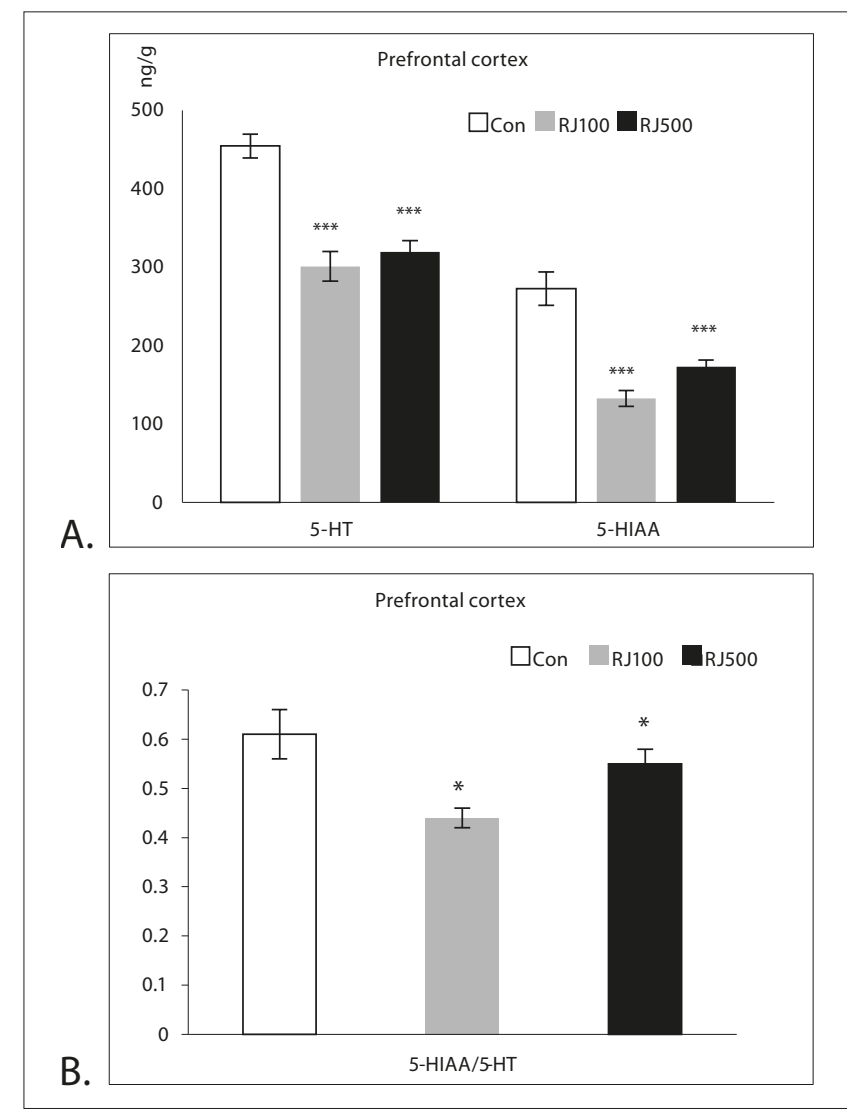

Figure 1. Effect of short-term 6-day administration of Royal Jelly on the level of neurotransmitters in the prefrontal cortex of aged male Wistar rats (Con: $n=7, R J 100$ : $n=8, R J 500: n=8): A$. serotonin (5-HT) and its metabolite 5-HIAA ( $\pm S E), * * * 0<0.001$ vs Con, MW test; B. serotonin turnover ( $5-\mathrm{HIAA} / 5-\mathrm{HT}),{ }^{*} \mathrm{p}<0.05$ vs Con, MW test.

A.
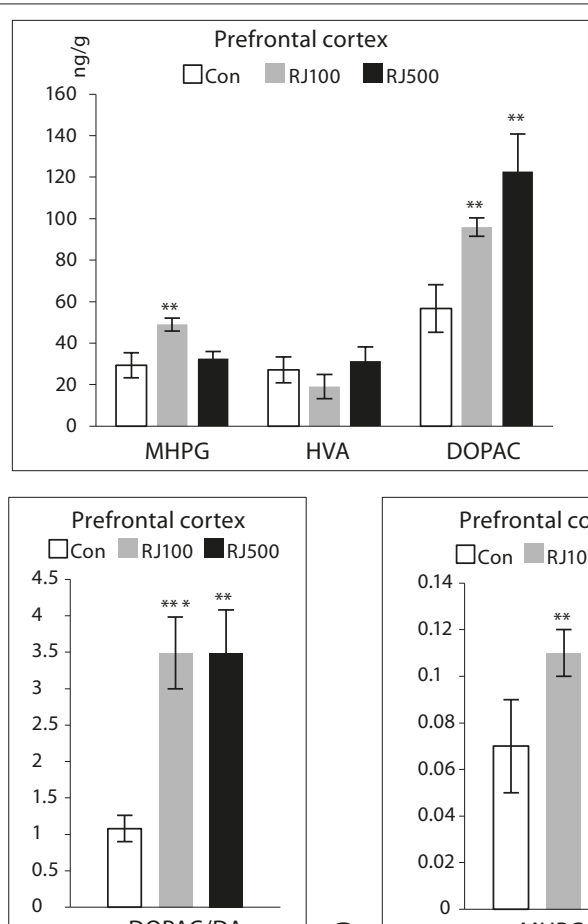

B. DOPAC/DA

C.

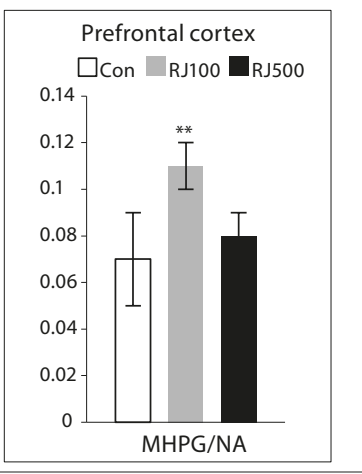

Figure 2. Effect of short-term 6-day administration of Royal Jelly on the level of noradrenaline and dopamine metabolites in the prefrontal cortex of aged male Wistar rats (Con: $n=7 ; R J 100: n=8 ; R J 500: n=8)$ : A. concentration of MHPG, HVA and DOPAC ( \pm SE); B - dopamine turnover (DOPAC/DA); C - noradrenaline turnover (MHPG/NA), ${ }^{* *} \mathrm{p}<0.01$ vs. Con, MW test; ${ }^{* * *} \mathrm{p}<0.001$ vs Con, MW test.

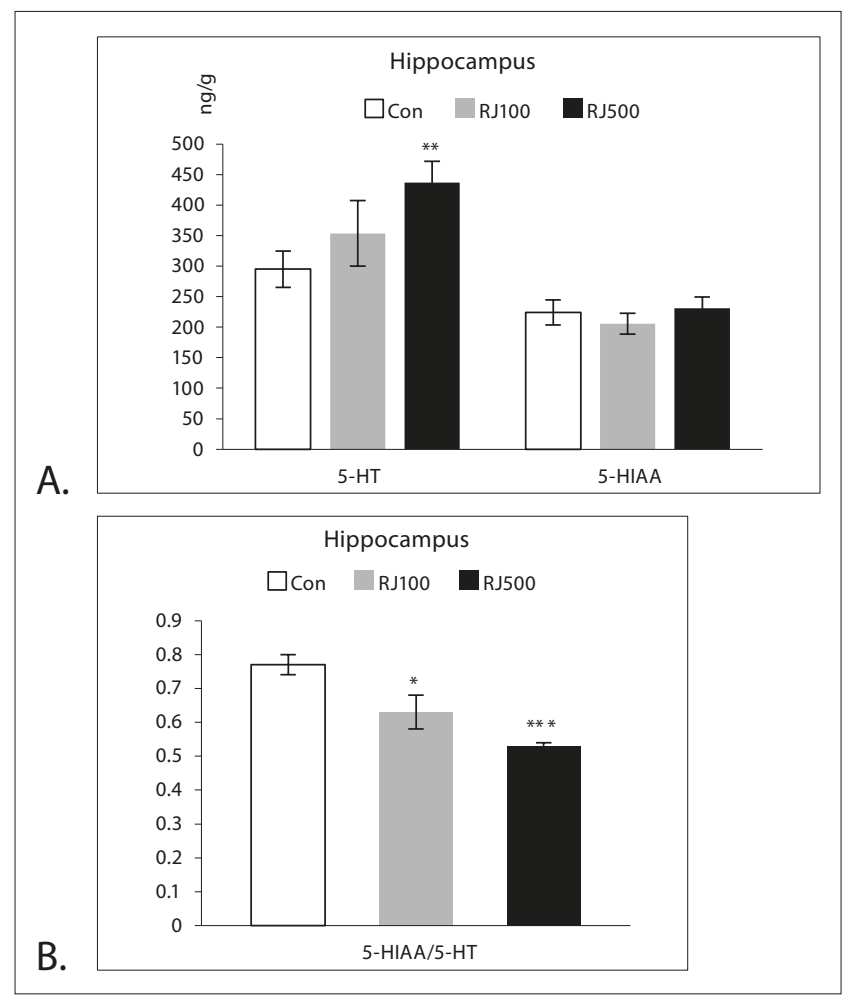

Figure 3. Effect of short-term 6-day administration of Royal Jelly on the level of: A. serotonin and serotonin metabolite; B. serotonin turnover - in the prefrontal cortex of aged male Wistar rats (Con: $n=8 ; R J 100: n=8 ; R J 500: n=8$ ), ${ }^{*} p<0.05$ vs. Con, MW test, ${ }^{* *} p<0.01$ vs. Con, MW test, ${ }^{* * *} p<0.001$ vs Con, MW test

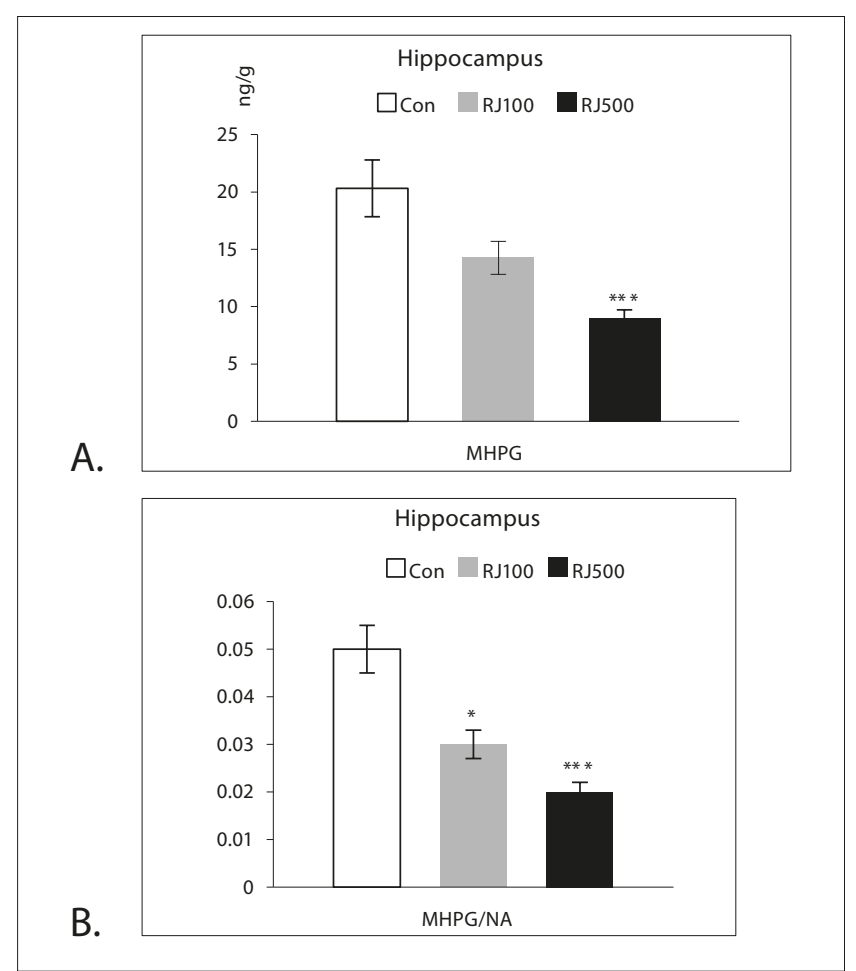

Figure 4. Effect of short-term 6-day administration of Royal Jelly on the level of: A. noradrenaline metabolite; $B$. noradrenaline turnover (MHPG/NA) in the prefrontal cortex of aged male Wistar rats (Con: $n=8 ;$ RJ100: $n=8 ; R J 500: n=8$ ), ${ }^{*} p<0.05$ vs. Con, MW test, ${ }^{* * *} \mathrm{p}<0.001$ vs. Con, MW test 


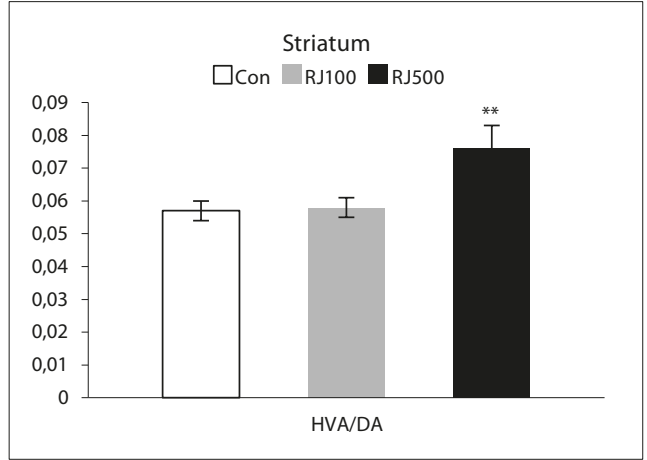

Figure 5. Effect of short-term 6-day administration of Royal Jelly on the level of dopamine turnover (HVA/DA) in the striatum of aged male Wistar (Con: $n=7 ; R J 100: n=8 ; R J 500: n=8$ ), ** $p<0.01$ vs. Con, MW test

\section{DISCUSSION}

The presented research examined 6-day Greek Royal Jelly administration impact on the central nervous system functions in naturally aged male rats. The authors' previous experiment on long-term RJ pre-treatment indicated spatial memory improvement in 18-month-old rats. Now, the water maze test showed that the short-term RJ treatment did not significantly influence spatial memory in aged rats. Both the acquisition and spatial navigation were the same in all evaluated groups of animals. All rats in the Visible Platform Test had the same values of latency, path to the target and swimming speed. It is apparent that their motivation, motor and visual abilities did not affect the results of the non-cued trials in the water maze.

Despite the fact no changes were observed in spatial behavior, the post-mortem examination revealed that RJ administered for such a short period of time was enough to start some alterations in the brain neurotransmitters content and their metabolism.

It was discovered that RJ significantly influenced serotonin concentration, just like in the case of its longterm administration. In this study, the rats given 100 and $500 \mathrm{mg}$ of RJ powder/kg b.w./day had decreased both 5-HT and its metabolite (5-HIAA) concentration in the prefrontal cortex (PF). The serotonin turnover also proved to be diminished. On the other hand, in the hippocampus (HIP) an increase in 5-HT content was observed, followed by a decrease of serotonin turnover in both tested groups of rats versus controls. Serotonergic transmission affects both the learning and memory processes, especially in the brain structures strongly involved in these functions - the prefrontal cortex and hippocampus. The role of serotonin in cognitive functions is considered to be rather intricated. Its effects seem to depend on the behavioural task and its motivational characteristics, engaging particular brain areas for solving the problem.

The hippocampus is mainly involved in formation of the spatial memory estimated in the hidden-platform task of water maze test, whereas the prefrontal cortex is rather concerned in short-term tasks. The improvement of spatial memory is usually related to the increased level of serotonin in the hippocampus $[11,12,13]$ and the impairment with its decrease, e.g. [14]; however, the correlation between 5-HT level in the hippocampus and spatial task performance may be lowered in ageing [15]. Less is known about the role of serotonin in the prefrontal cortex and its influence on working memory. The research results of serotonin impact are elusive - its depletion was linked either with improvement in short-term memory behavioural performance in lesioned rats [16], or an impairment when the egocentric strategies were used for solving the problem [17].

Short-term RJ treatment did not change the level of dopamine and noradrenaline, although their metabolism was altered in the prefrontal cortex, hippocampus and striatum. In the PFC, increased DOPAC concentration and dopamine turnover were noted in both the RJ100 and RJ500 groups, as well as the MHPG level and NA turnover in RJ100 rats when compared to the control animals. Such greater values of DOPAC and DOPAC/DA ratio were also seen after chronic RJ administration in the previous study. In the HIP, noradrenaline metabolism was diminished in all tested rats versus controls, but the dopamine one was not affected. The striatum of rats receiving the greater dose of RJ had elevated HVA/DA ratio values. Catecholamines play an important role in cognitive performance. The prefrontal cortex is innervated and modulated by different pathways, especially the afferent fibres from the dopaminergic ventral tegmental area (VTA) and noradrenergic locus coeruleus (LC). Dopamine signaling in the prefrontal cortex is associated with working memory, attention, reward-based learning, and also with memory consolidation $[18,19]$. Noradrenaline is implicated in experience-dependent alterations and in attention behaviour [20]. Both too high, pathological or stress-related levels, as well as too low concentrations of dopamine and noradrenaline, are able to affect the working memory and decrease cognitive performance $[21,22,23]$, but the optimal level of catecholamines in PFC improves spatial working memory. The HIP, the same as PFC, receives noradrenaline input from the LC and plays a role in the consolidation of information, and thus memory formation and learning. Raised NA release is able to cause a memory-enhancing effect. It is known that animal behaviour may also be affected by the change of catecholamine turnover, which may reflect the efforts to maintain their previous concentration in the nervous tissue or higher neuronal activity. Murphy et al. [24] described that a greater DA utilisation in PFC considerably disrupted spatial working memory task in rats, but had no influence on the spatial discrimination task that was not PFCdependent. That is a further argument for additional studies to fully characterize the potentially unique behavioural responses after RJ administration. In any case, even mild stress can cause an increase in monoamine metabolism in the prefrontal cortex and in the hippocampus, affecting behavioural performance [25].

In the presented experiment, all animals, including controls, underwent the same procedures involving drug administration and water maze test, so that their level of stress was the same.

Despite the fact that no modification of spatial memory was observed in the water maze test, the fast alteration in the serotonergic, dopaminergic and noradrenergic neurotransmission indicate the potential influence of the RJ on cognitive performance. Furthermore, the neurochemical results indicate the need for appraisal of the working memory in other behavioural tests. 


\section{CONCLUSIONS}

The presented research findings indicate that 6-day Greek Royal Jelly administration is sufficient to initiate some subtle neurochemical changes in the central nervous system of old male rats, comprising mainly of serotonergic and dopaminergic transmission. The short period of RJ treatment, however, is inadequate to affect the spatial memory of aged WAG male rats, as shown in the Morris water maze. In view of the specific neurochemical modifications in the prefrontal cortex there is a need for detailed examination of rats' working memory in behavioural tests.

\section{Acknowledgements}

The authors express their thanks to the ATTIKI Bee Culturing Co., Alexandros Pittas SA, for the gift of the Greek Royal Jelly used in the research. The donor, however, had no involvement in any stage of research. The research subject was implemented with CePT infrastructure financed by the European Union - the European Regional Development Fund within the Operational Programme 'Innovative economy' for 2007-2013.

\section{REFERENCES}

1. Viuda-Martos M, Ruiz-Navajas Y, Fernández-López J, Pérez-Álvarez JA. Functional Properties of Honey, Propolis, and Royal Jelly. J Food Sci. 2008; 73(9): R117-R124.

2.Zamami Y, Takatori S, Goda M, Koyama T, Iwatani Y, Jin X, et al. Royal Jelly ameliorates insulin resistance in fructose-drinking rats. Biol Pharm Bull. 2008; 31(11): 2103-2107.

3. Hattori N, Nomoto H, Mishima S, Inagaki S, Goto M, Sako M, Furukawa S. Identification of AMP N1-oxide in royal jelly as a component neurotrophic toward cultured rat pheochromocytoma PC12 cells. Biosci Biotech Biochem. 2006; 70(4): 897-906.

4. Ito H, Nakajima A, Nomoto H, Furukawa S. Neurotrophins facilitate neuronal differentiation of cultured neural stem cells via induction of mRNA expression of basic helix-loop-helix transcription factors Mash1 and Math1. J Neurosci Res. 2003; 71(5): 648-658.

5. Hattori N, Nomoto H, Fukumitsu H, Mishima S, Furukawa S. RJ and its unique fatty acid, 10-hydroxy-trans-2-decenoic acid, promote neurogenesis by neural stem/progenitor cells in vitro. Biomed Res. 2007; 28(5): 261-266.

6. Hattori N, Ohta S, Sakamoto T, Mishima S, Furukawa S. RJ facilitates restoration of the cognitive ability in trimethyltin-intoxicated mice. Evid Based Complement Alternat Med. 2011; doi: 10.1093/ecam/nep029 (ID 165968).

7.Zamani Z, Reisi P, Alaei H, Pilehvarian A, Zamani Z. Effect of Royal Jelly on spatial learning and memory in rat model of streptozocininduced sporadic Alzheimer's disease. Adv Biomed Res. 2012; 1: 26. doi: 10.4103/2277-9175.98150.
8. Peng Y, Zhong F, Yang B, Gao R, Su F. Effect of Royal Jelly on learning and memory performance of aged rats. Food Sci. 2011; 32: 269-272.

9. Pyrzanowska J, Piechal A, Blecharz-Klin K, Joniec-Maciejak I, Graikou K, Chinou I, Widy-Tyszkiewicz E. Long-term administration of Greek Royal Jelly improves spatial memory and influences the concentration of brain neurotransmitters in naturally aged Wistar male rats. J Ethnopharmacol. 2014; 155(1): 343-351.

10. Glovinsky J, Iversen LL. Regional studies of catecholamines in the rat brain: The disposition of [3H]-NA, [3H]-DA and [3H]-DOPA in various regions of the brain. J Neurochem. 1966; 13: 655-669.

11. Richter-Levin G, Segal M. Serotonin, aging and cognitive functions of the hippocampus. Rev Neurosci.1996; 7(2): 103-113.

12. Carli M, Balducci C, Samanin R. Stimulation of 5-HT(1A) receptors in the dorsal raphe ameliorates the impairment of spatial learning caused by intrahippocampal 7-chloro-kynurenic acid in naive and pretrained rats. Psychopharmacology (Berl). 2001; 158(1): 39-47.

13. Haider S, Khaliq S, Haleem DJ. Enhanced serotonergic neurotransmission in the hippocampus following tryptophan administration improves learning acquisition and memory consolidation in rats. Pharmacol Rep. 2007; 59(1): 53-57.

14. Sprague JE, Preston AS, Leifheit M, Woodside B. Hippocampal serotonergic damage induced by MDMA (ecstasy): effects on spatial learning. Physiol Behav. 2003; 79(2): 281-287.

15. Oliveira L, Graeff FG, Pereira SR, Oliveira-Silva IF, Franco GC, Ribeiro AM. Correlations among central serotonergic parameters and agerelated emotional and cognitive changes assessed through the elevated T-maze and the Morris water maze. Age (Dordr). 2010; 32(2): 187-196.

16. Pérez-Vega MI, Feria-Velasco A, González-Burgos I. Prefrontocortical serotonin depletion results in plastic changes of prefrontocortical pyramidal neurons, underlying a greater efficiency of short-term memory. Brain Res Bull. 2000; 53(3): 291-300.

17. González-Burgos I, Fletes-Vargas G, González-Tapia D, GonzálezRamírez MM, Rivera-Cervantes MC, Martínez-Degollado M. Prefrontal serotonin depletion impairs egocentric, but not allocentric working memory in rats. Neurosci Res. 2012; 73(4): 321-7.

18. Williams GV, Goldman-Rakic PS. Modulation of memory fields by dopamine D1 receptors in prefrontal cortex. Nature. 1995; 376 (6541): 572-575.

19. Wise RA. Rewards wanted: Molecular mechanisms of motivation. Discov Med. 2004; 4(22):180-186.

20. Berridge CW, Waterhouse BD. The locus coeruleus-noradrenergic system: modulation of behavioural state and state-dependent cognitive processes. Brain Res Brain Res Rev. 2003; 42(1): 33-84.

21. Arnsten AF, Li BM. Neurobiology of executive functions: catecholamine influences on prefrontal cortical functions. Biol Psychiatry. 2005; 57(11): 1377-1384.

22. Ramos BP, Arnsten AF. Adrenergic pharmacology and cognition: focus on the prefrontal cortex. Pharmacol Ther. 2007; 113(3): 523-536.

23. Vijayraghavan S, Wang M, Birnbaum SG, Williams GV, Arnsten AF. Inverted-U dopamine D1 receptor actions on prefrontal neurons engaged in working memory. Nat Neurosci. 2007; 10(3): 376-384.

24. Murphy BL, Arnsten AF, Goldman-Rakic PS, Roth RH. Increased DA turnover in the PFC impairs spatial working memory performance in rats and monkeys. Proc Natl Acad Sci USA. 1996; 93(3): 1325-1329.

25. Dent MF, Neill DB. Dose-dependent effects of prefrontal dopamine on behavioural state in rats. Behav Neurosci. 2012; 126(5): 620-39. 